\title{
Diante da perda do arquivo: reinvenções e narrativas da memória
}

\begin{abstract}
Maria Ivone dos Santos*
\section{Resumo:}

O relato recente da artista Sophie Hemon sobre a perda total de seus arquivos de imagens nos lança diretamente na problemática relacionada à memória e à sua reconstrução. Partindo desta introdução circunstancial, observaremos a noção de edição, com base nas análises de práticas artísticas contemporâneas. A partir de Edward Ruscha, passando por Bernd e Hilla Becher, por Boltanski, Richter e Lara Almarcegui, buscaremos tecer uma reflexão sobre a constituição de arquivos na arte contemporânea e sobre a potência da articulação discursiva de certas imagens e de seus agenciamentos, seja em uma exposição, seja em uma publicação. Como estas práticas de re-singularização do mundo são devolvidas enquanto obra ao mundo e que outras questões trazem ao campo da arte e da cultura?
\end{abstract}

\section{Palavras-chave:}

Arte contemporânea; arquivo; memória; edição; publicação

O que fazer diante da perda de um arquivo? Como transmitir e conservar nossa memória e o nosso estar no mundo? Uma amiga, a artista francesa Sophie Hemon, contou-me com certo pavor o branco que Ihe sucedeu diante da perda das pastas com as imagens armazenadas em seu computador. Nos arquivos ordenava e compunha um singular arranjo de suas lembranças de vida. Eram centenas, se não milhares, de fotografias e pequenos comentários que mostravam o exterior de um parque em Praga, as cerejeiras em flor encontradas nos arredores de Paris onde vive, os amigos e registros de aspectos notáveis de suas várias viagens ao Brasil, em Fortaleza e Porto Alegre. Todos estes registros e notas desapareceriam de sua vista e ela teria que encontrar um modo de retraçar as experiências que para ela tinham sido tão importantes.

Assim, seria preciso entender que a dimensão temporal de nossa experiência no mundo se esvai quando perdemos os documentos, permanecendo talvez a capacidade de retraçar uma experiência por novos modos de narração. Os arquivos de imagens, os álbuns e as coleções de objetos de nossa cultura material pareceriam cumprir esta função de testemunho, podendo servir de suporte de uma narração. Walter Benjamim nos diria que a memória é ao mesmo tempo crítica e afetiva, pois, se movida por um ato de vontade, ela é ao mesmo tempo atravessada por elementos involuntários.

Observaremos neste texto dois conjuntos de problemáticas artísticas que se ocu-

* Doutora em Artes, Professora do PPG Artes Visuais da UFRGS, Grupo de Pesquisa Veículos da Arte. 
pam em articular a idéia de constituição de uma memória. Veremos como alguns artistas buscaram apresentar, remontar, repertoriar e discutir sua experiência, tanto individual quanto histórica, repensando estratégias de compartilhamento de seu estar no mundo. Os exemplos que analisaremos, tanto os que envolvem a difusão pela via da publicação, quanto os que se mostram em exposições, evidenciam o interesse crescente desses artistas em agenciar os conteúdos para além da informação hegemônica. Buscando apresentar temas muitas vezes periféricos, ou recordando temas polêmicos, veremos o artista agindo fora de um sistema das Belas Artes, quando, por suas habilidades e capacidades persuasivas, era convidado a montar uma situação histórica precisa como representação.

Esses exemplos surgem também a partir de uma cisão de certos artistas com as correntes abstracionistas e formalistas defendidas anteriormente pela crítica de arte norte-americana e que deram energia ao movimento de resistência, com um enfoque mais conceitual e crítico que buscava dar atenção aos contextos de inserção da obra, e que pensava tanto nos meios de comunicação quanto nas questões da arte e da cultura.

Veremos não somente que a posição do enunciador mudou, com também os seus gestos, fazendo com que os artistas incluam cada vez mais a fotografia em seus processos. Limitamo-nos a observar as práticas que ocorreram a partir dos anos 1960 do século XX. Escolhemos os trabalhos de Edward Ruscha, Bernd e Hilla Becher, artistas que agem como inventariantes, narradores e editores de certo olhar sobre o mundo; Christian Boltanski e Gerhard Richter, artistas que, respectivamente, agem como narradores e colecionadores; Lara Almarcegui, que proporciona outra leitura dos lugares naturais e culturais presentes em nosso cotidiano, pontuando contradições e propondo modos de resistência aos processos de naturalização. Veremos, igualmente, que estas práticas artísticas impactaram o campo da própria arte, alargando seus limites e âmbitos, discutindo e trazendo elementos para pensar criticamente a própria cultura.

Um primeiro exemplo é o livro de Edward Rusha, intitulado Twentysix gasoline stations, de 1963 (off-set, 18×24cm, 48 páginas). Com finalização sóbria, contém 26 fotografias que retratam os postos de gasolina e as poucas edificações encontradas num contexto desértico, efetuadas durante deslocamento realizado pelo artista na mítica rota 66, entre Los Angeles e Oklahoma. Conforme sabemos do artista, as paradas obrigatórias nestes locais motivariam a tomada das imagens que iriam descrever o espaço de modo quase literal. As legendas sinalizariam a localização geográfica no território.

Quando vemos a seqüência de imagens sendo mostradas nas páginas do livro, somos levados a pensar que o artista optou por uma montagem sucessiva, um posto depois do outro, tal como apareciam em seu deslocamento. Mas, se observarmos mais atentamente, nós veremos que ele optaria por organizá-las embaralhando um pouco a ordem. Esta interferência na ordem é o que reduz o estatuto puramente documental e uma funcionalidade descritiva aos quais poderíamos remeter esta publicação. Não somente o trabalho agencia um olhar, como o reordena segundo critérios muito pessoais e subjetivos (SILVEIRA, 2008, p. 60 e 67). 


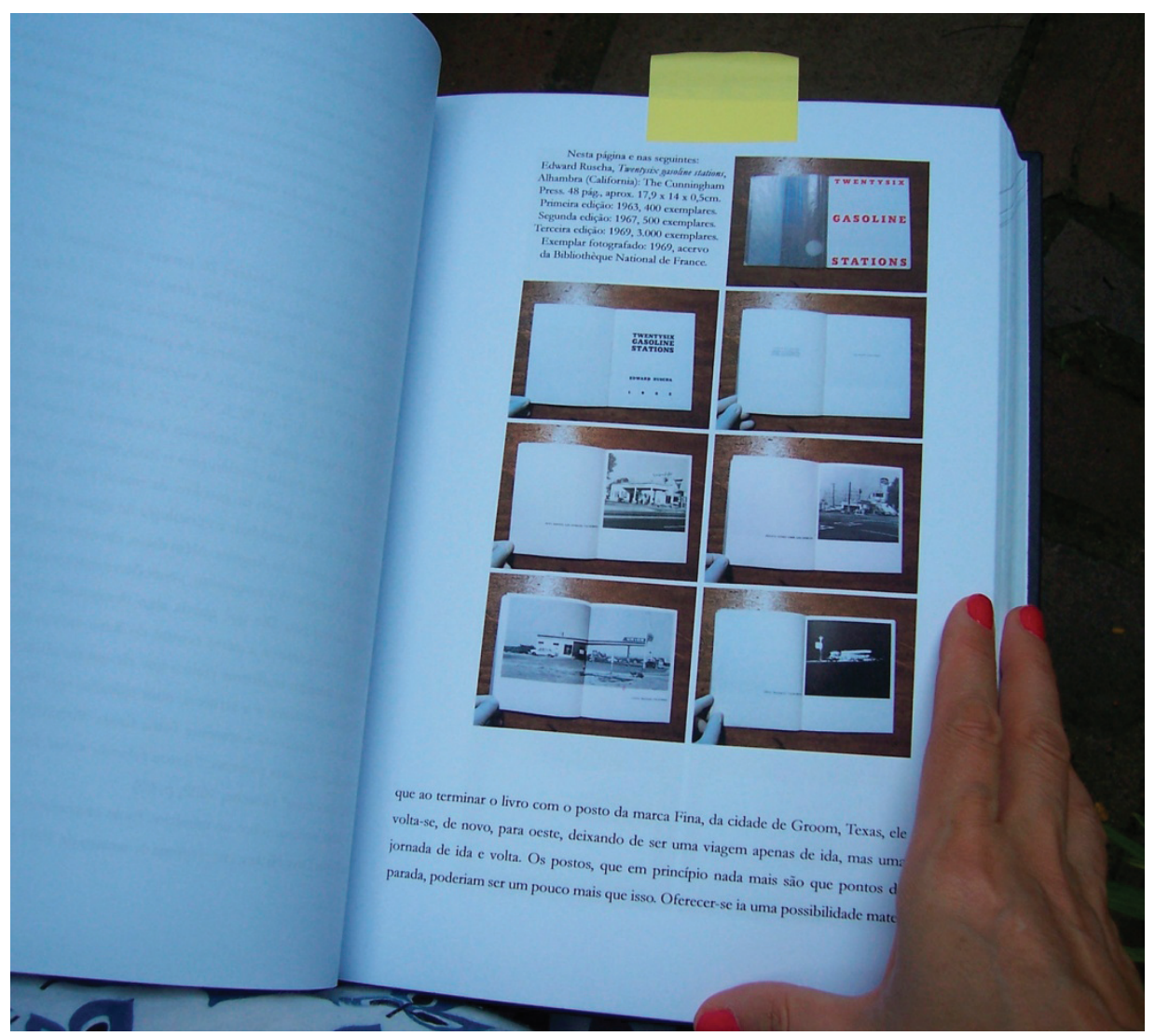

Figura 1: Edward Rusha, Twentysix gasoline stations

Fonte: Tese de Paulo Silveira, 1963.

Já em outra série de livros, o artista estaria atento aos lugares onde circulava a sua transformação, seguindo uma estratégia de observação, transposição e montagem de fotografias para as páginas de uma publicação. Assim é que produz Every building on the sunset strip (1966) e Feel palms trees (1971), nos quais introduz não somente um foco sobre uma situação precisa, quanto a delimita, temporalmente falando. À medida que os anos passam, essas imagens vêm adquirindo uma função distinta. Se, num primeiro momento, elas transcreviam quase que literalmente estes lugares, o que dizer se observarmos estes mesmos lugares hoje?

O enfoque do banal (para muitos) mostra que o artista encontraria no veículo publicação uma forma de conservar e praticar a difusão de um ponto de vista notável para ele. Multiplicado pela edição, cada exemplar passa a ser um lugar de partilha, visto que o livro múltiplo descentra a problemática da exposição. É importante salientar também que esses livros remetem a uma experiência subjetiva dos espaços comuns (uma estrada, uma cidade), mas os mostram sem enfocar a representação humana. Ruas e fachadas agem como testemunhos de cenários de vida que o artista defende como (RUSCHA, 1966 apud STILES; SELTZ, 1996, p. 357) "uma coleção de fatos".

Estes trabalhos, tais como são apresentados, chamam a atenção para dois gestos importantes a destacar no campo da arte. O primeiro denota o interesse do artista 
em praticar uma autonomia quanto à escolha de seus temas, centrando-se no seu cotidiano e no seu estar no mundo. O segundo gesto seria o de buscar, pela via da publicação, fazer a distribuição simbólica de seu olhar, desenhando através da difusão outras estratégias de contato com seu público que não passariam apenas pelo sistema estabelecido das galerias e exposições. Isto denota que o artista assumia assim uma posição política.

Paulo Silveira, pesquisador que vem se dedicando ao modo publicação e dando especial atenção às narrativas de artistas, apresenta em sua tese de doutorado uma discussão acerca das nuances da opção pela publicação por parte dos artistas. ${ }^{1} \mathrm{Em}$ muitos casos, em sua opinião, o livro surge como um escape à questão do circuito da arte e como um espaço de aventura em outra realidade. Seguindo uma definição mais pontual ainda, o livro seria o lugar que "acolhe a série e que transporta os significados" (SILVEIRA, 2008, p. 93).

O autor defende que as publicações de Ruscha (Idem, p. 60) - livretos, como os define - "são de fato trabalhos poderosos, com competência para ajudar a arte a andar um pouquinho mais". Os livros impressos tornam mais complexa sua inserção dentro do que se costuma referenciar como livros artesanais feitos por artista. Obedecem a outra lógica quanto à fatura, visto que incluem processos de editoração e impressão industrial. Ao eliminarem igualmente o valor atribuído a uma obra única, a uma pintura, e ao atribuir diferentes valores a uma série fechada de fotografias, eles problematizam a idéia de obra. O trabalho se descentra do circuito de validação e se aventura em outros sistemas, como os de uma biblioteca, por exemplo.

Mas a pertinência incerta desta prática, e o seu custo e o aspecto modesto a barrariam da inserção desejada pelo artista na Biblioteca do Congresso nos Estados Unidos. Este fato, porém, motivaria outra posição do artista, que faria um anúncio desta rejeição e um oferecimento dos exemplares na revista Artforum, em março de 1964, cuja repercussão foi imediata no campo da arte, conforme nos relata Silveira (Ibid., p. 71). ${ }^{2}$ A clareira aberta pelas publicações de Ruscha levaria outros artistas a se aventurarem nos veículos do livro impresso, alterando gradualmente os parâmetros do que é convencionado como arte.

O que nos parece fundamental entender no sistema livro é que ele encadeia uma temporalidade própria, dada pelo arranjo, pela união das páginas, criando assim um todo seqüencial. Neste modo, se exploraria a noção de edição, particularmente em relação àquilo que se escolhe, ao que se organiza e ao que se situa. A página definiria o "estatuto especial, um momento de uma condição. Lugar, tempo ou

\footnotetext{
1 Na tese de doutorado, As existências da Narrativa no Livro de Artista, Paulo Silveira privilegia um olhar sobre os livros de artista impressos. O estudo faz um aprofundamento de um tópico anunciado no minucioso levantamento realizado anteriormente a 2001, durante mestrado, e que culminou na publicação do livro A página Violada: da ternura à injúria na construção do livro de artista. O autor integra o Grupo de Pesquisa Veículos da Arte (UFRGS/CNPq).

2 "Movido pelo fato, Ruscha mandou publicar um pequeno anúncio de $12,7 \times 5,7 \mathrm{~cm}$ na revista Artforum, de março de 1964, promovendo o livro a partir desta recusa. O título do anúncio era: "Rejeitado, 2 out. 1963, pela Biblioteca do Congresso Washington 25, D.C". Embaixo, uma foto do livro, seguro em sua mão, seguida de mais texto, cópias disponíveis por três dólares e os endereços para pedidos em Los Angeles e Nova York".
} 
modo que a privilegiam como suporte à narração," segundo Silveira (Ibid., p.112). Já a noção de edição, no caso do livro impresso, adquire um segundo sentido para além do encadeamento narrativo, operado por cortes e pela montagem dos conteúdos com vistas a dirigir o olhar. A edição é também aqui compreendida como a multiplicação de um original em um determinado número de exemplares, o que define também uma ambição da abrangência desse original.

Vejamos agora a prática fotográfica desenvolvida por Bernard e Hilla Becher, ${ }^{3}$ que há mais de 40 anos vêm trabalhando sobre um tema que interessa ao enfoque da memória, do arquivo e da publicação. Sob a rubrica Typologies, estes dois artistas se dedicam a uma pesquisa cuja pré-produção é tão importante quanto as fotografias dela decorrentes. Outro livro, Anonyme Sculptures, é constituído por uma série de fotografias tomadas nas principais regiões industriais da Europa. ${ }^{4}$ Ordenadas por seqüências de imagens que formam capítulos, as imagens são acompanhadas de uma legenda muito discreta, que indica o local da tomada e a data. Com afã memorialista, os Becher irão produzir um inventário de edifícios em obsolescência, mas que persistem pela sua monumentalidade nos nossos cenários de vida, trazendo ao presente o testemunho de modos de vida do passado.

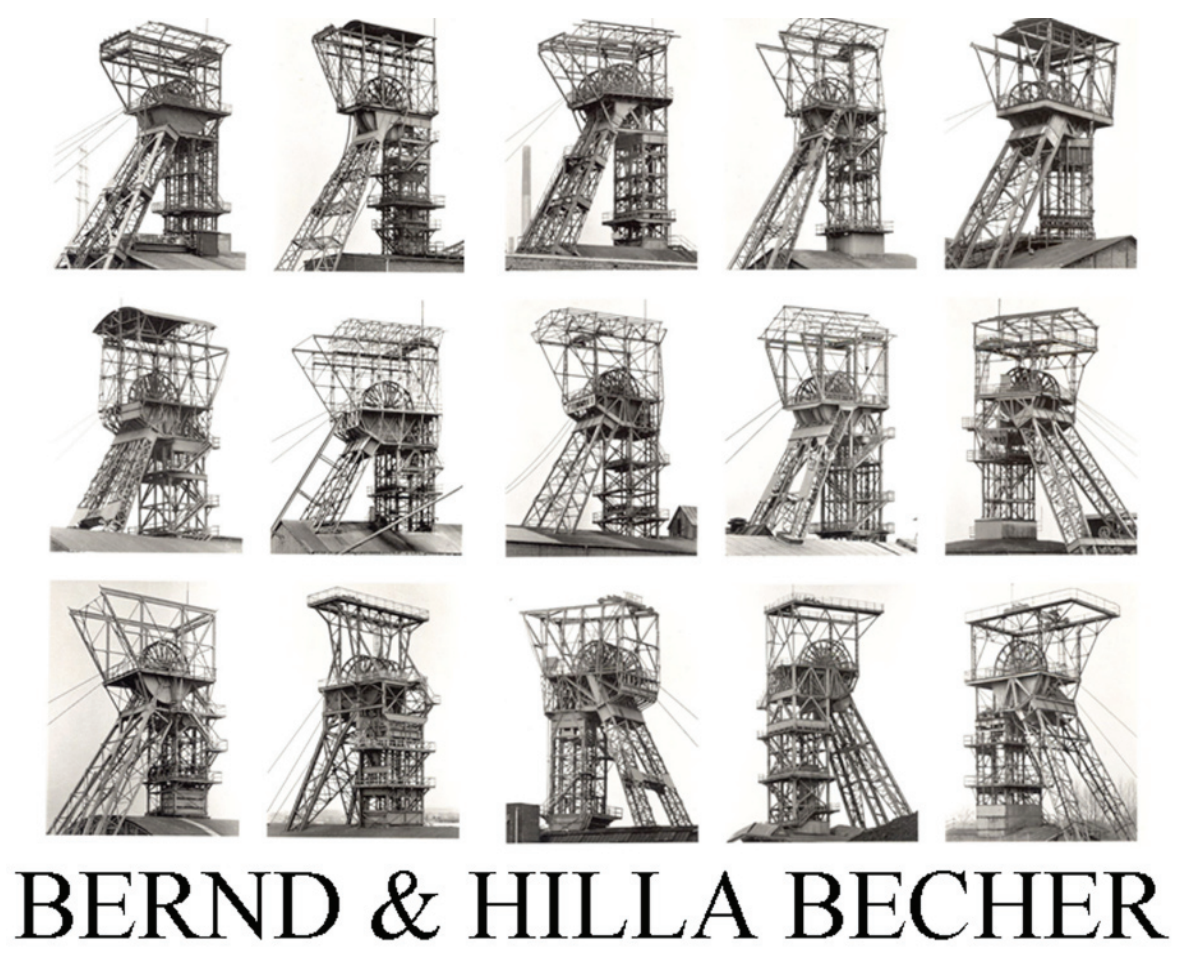

\section{TIPOLOGIE TYPOLOGIEN TYPOLOGIES}

Figura 2: Capa do catálogo. Bernd \& Hilla Becher - Typologies.

Fonte: Munich: Shirmer/Mosel, 1990.

\footnotetext{
${ }^{3}$ As fotografias são mostradas em exposição, sendo beneficiadas de uma visibilidade considerável também como livros impressos. O metódico trabalho de Bernd e Hilla Becher começou em 1970. Eles representaram a Alemanha, em 1990, na Bienal de Veneza, tendo recebido o grande prêmio de escultura com um trabalho em fotografia, o que os tornou mundialmente conhecidos. ciado por Moeglin-Delcroix no capítulo intitulado Le modèle des sciences, le modele du musée.
} 
Esta ampla pesquisa culmina na partilha de temas pertencentes à memória coletiva mostrados em exposições, mas que parecem adquirir uma potência crítica fenomenal quando publicados. Esta fotografia, descritiva e documental, surge como uma prática necessária face à transitoriedade crescente das formas do mundo. As imagens das torres de água enfileiradas lado a lado apresentam diferenças quanto a suas formas e aspectos, mas a imagem encontra-se carregada de sentidos vindos da cultura, posto que nos serve de suporte a uma rememoração.

Os Becher nos convidam a reconhecer, nas "esculturas anônimas" e nas construções que apresentam, as funções e os usos que vêm desaparecendo: os poços das minas que estavam fechando; as caixas d'água obsoletas que talvez desaparecessem sem deixar vestígios. Pelo trabalho destes artistas, elas passam a integrar o vasto inventário que se disponibiliza à nossa atenção e cuidado. Segundo salienta Anne Moeglin-Delcroix (1997, p. 217), a posição de leitura e o encadeamento das páginas do livro, o ir e o vir, bem como o ato de folhear, remeteriam aos processos de apagamento e de encobrimento que ocorrem em nossa cultura. A publicação permitiria uma apreciação crítica sobre o que desejamos conservar, visto que testemunha as obras da aventura humana.

Por outro lado, o artista francês Christian Boltanski toma emprestado, da ciência, seu modelo classificatório, e, da cultura, suas imagens e fatos para reapresentar narrativas de aspectos obscuros de nossa história coletiva. Jiri Svestka (1988, p. 97), ao escrever sobre uma exposição do artista, realizada em 1988, adverte: "A função da arte não é transmitir fatos ou informações, mas sobretudo colocar problemas, formular questões ou criar situações. (...) a pluralidade de significações da obra sendo a condição mesma de sua existência". ${ }^{5}$ A descrição de uma exposição de Boltanski nos mostrará de que forma o artista irá jogar luz sobre uma situação da história, uma vez que esta é uma experiência da qual ele não participou diretamente, mas que ela remonta e assim remete a acontecimentos que nos são comuns. "Gestos como colher, recolher, colecionar são estados de uma compreensão empírica da ciência" e que a toma por modelo, como escreve Anne Moeglin-Delcroix (1997, p. 218).

\footnotetext{
${ }^{5}$ A retrospectiva de Boltanski, aqui descrita, foi mostrada em museus dos Estados Unidos e da Europa, tendo sido iniciada no Museu de Arte Contemporânea de Chicago em 22 de abril e concluída em 19 de junho de 1988, daí seguindo para Madrid, no Centro Reina Sophia, na Espanha.
} 


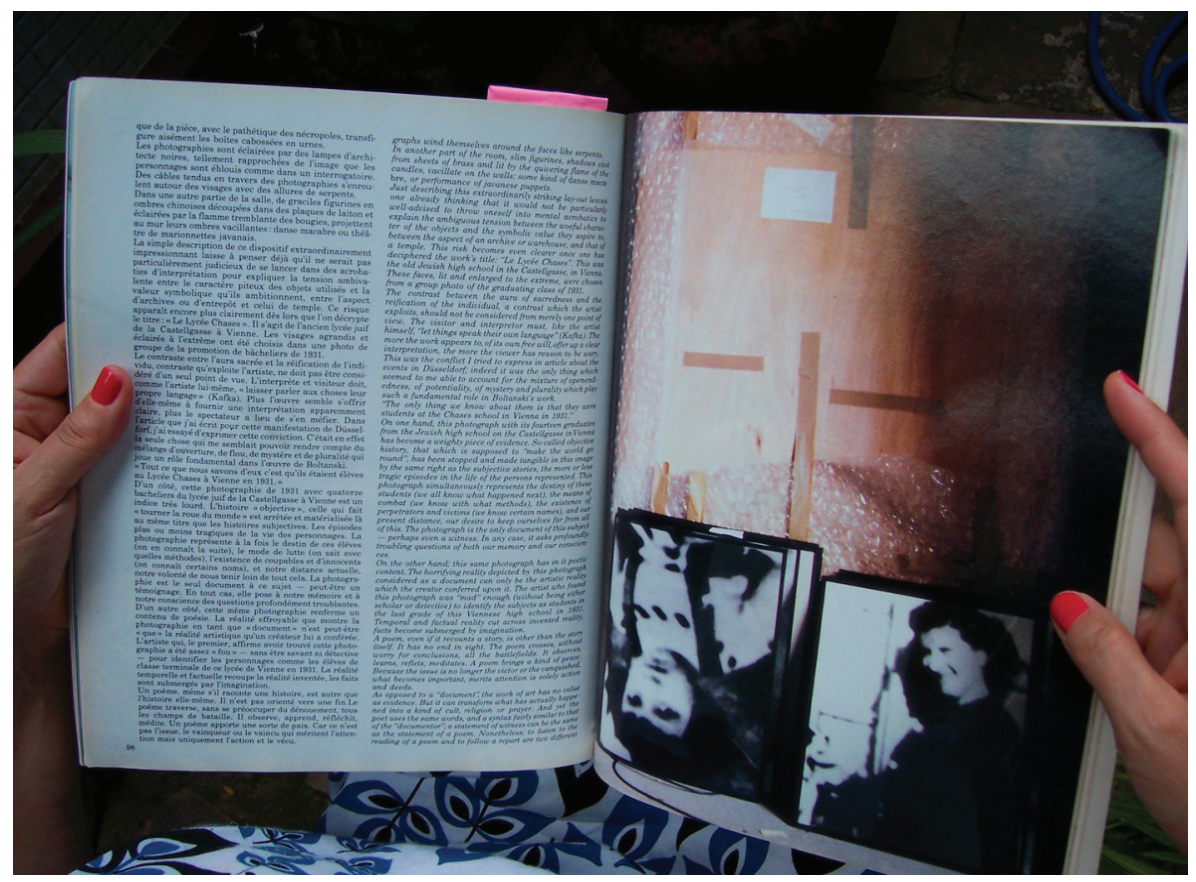

Figura.3: Christian Boltanski, vista do atelier, Galeries Magazine 1988 Fonte: Fotografia de Charles Dolfi-Michel.

Imaginemos entrar em uma sala cuja atmosfera é muito escura, com janelas fechadas para que a luz não penetre. Este ambiente, que mais se aparenta com catacumbas, é também uma sala fria, na qual se percebe ao fundo um arranjo de lâmpadas iluminando uma série de imagens. São rostos de jovens, empilhados uns sobre os outros, formando uma espécie de altar. Mas as fotografias estão desfocadas, o que as torna irreconhecíveis. Mesmo assim, podemos adivinhar que alguns estão sorrindo. Os objetos que serviram de suporte às imagens parecem caixas de metal para guardar bolachas, o que nos remete a um passado e a uma prática de aproveitamento e de reciclagem. Estas caixas eram seguidamente aproveitadas para guardar objetos, lembranças, cartas, tornado-se cofres de relíquias. A presença muito próxima das lâmpadas faz-nos crer que as imagens estão sendo interrogadas, como numa sessão de investigação policial. Noutra parte da sala, uma lâmpada próxima ao chão ilumina um pequeno teatro de sombras: figurinhas feitas de arame tremem e se projetam nas paredes, criando situações fantasmagóricas.

O espaço expositivo se investe de um estatuto ambíguo, um misto de arquivo, depósito e templo. A instalação mostra, de forma bastante complexa, um intrincado jogo de rememoração que se revela no título da instalação "Les lycées Chasses", e relembra a escola judia Castelgasse, em Viena. As imagens alteradas que ali se encontram foram retiradas de uma fotografia que mostrava uma turma de 14 alunos judeus, escolares desta escola em 1931. Isto é tudo o que sabemos deles. O que pareceria claro - considerar a fotografia um documento -, "neste contexto induz a uma desconfiança por parte do espectador que poderia se perguntar se 
são verdadeiras ou não" (SVESTKA, 1988, p. 98).

A fotografia parece suspender o destino destes estudantes (principalmente se sabemos da história que se sucedeu a este período da história), pois, a partir dela, o artista pode reconstruir uma situação dolorosa de se enfrentar. Assim instaladas, elas parecem destilar um destino amedrontador, como as sombras avivadas pela lembrança dos fatos.

O artista admite sua loucura ao colocar em funcionamento uma imagem tirada da realidade e com ela produzir uma ficção, um teatro de sua própria memória. No entanto, a instalação das imagens e objetos assim dispostos e iluminados parece funcionar como uma potente forma de ativação da imaginação. Distante do documento, a obra de arte não pretende ter um valor de prova, nem nesta montagem, nem em outros trabalhos de Boltanski. Pensamos que a arte seria para ele este outro modo de distanciamento que, no entanto, teceria proximidades e familiaridades com nosso imaginário comum. Caberia à arte a função de iluminar a memória? Entre o autêntico documento e a percepção dele na instalação, o que é apresentado à imaginação oscila e atua de forma que o objetivo e o subjetivo da questão ficassem equivalentes, tratados de igual para igual. Seria dada a este artista a oportunidade de transformar o testemunho em relíquia?

Mesmo que não reconheçamos alguém diretamente nestas imagens, elas nos remetem a gestos e fatos que nos são comuns. $O$ artista confidencia como manter certa vigilância sobre o que não deve ser jamais esquecido (Idem, p. 103): "Da mesma forma que todos nós partilhamos um mesmo fundo cultural, nós acabaremos, penso eu, num mesmo museu". ${ }^{6}$ O museu, um lugar onde uma cultura guarda e exibe o que há de ficar para ser revisto e rememorado.

O artista alemão Gerhard Richter ${ }^{7}$ busca igualmente pensar na possibilidade de constituir um acervo muito vasto, no qual deseja colocar lado a lado imagens da cultura, imagens veiculadas na imprensa e fotografias de seu cotidiano, fazendoas conversarem com sua prática da pintura. Segundo Bernard Blistène (1988, p. 91), "o artista seguiria um pintor na era da reprodução". Vemos, assim, Richter com o seu Atlas (1998, 388 páginas), trabalho iniciado em 1962, constituído com atento cuidado do artista, que organiza pranchas com diversos temas, reunindo desde fotografias da natureza até recortes de jornal e de revistas, ou colagens que simulam montagens destas imagens em galerias. No Atlas, sob o número 28, o artista mostra a foto do líder comunista chinês Mao Tsé-Tung. Esta imagem é desfocada e ampliada pelo artista. Na prancha 41, veremos um desdobramento expositivo destas imagens, as quais formam uma galeria de personagens retira-

6 "De même que nous partageons tous le même fonds culturel, nous finirons, je pense, au même musée» (Tradução nossa).

7 Gerhard Richter nasceu em Dresden em 1932, tendo em sua juventude vivido muitas contradições. Sabe-se que em sua família havia parentes que aderiram ao nazismo, sendo que um tio morreu jovem nos campos de batalha, mas uma tia foi morta nos campos nazistas por ser doente mental. Desta desilusão ideológica nasceria sua convicção de trabalhar de forma indistinta temas e fatos sem celebração nem glória. Quando deixou a Alemanha oriental para viver em Dusseldorf, passou a trabalhar com um grupo de outros artistas reunidos sob o nome de Capitalist realist que privilegiavam como temas as imagens das mídias. Sugerimos consultar o site do artista no qual é possível aceder à complexidade deste acervo de imagens, bem como às inúmeras referências bibliográficas de autores que se debruçam sobre a obra deste artista. http://www.gerhard-richter.com 
dos de enciclopédias e livros de história. Nas pranchas numeradas de 92 a 105, vemos o artista exibindo fotografias de pinceladas generosas, de pigmentos cujas formas a nada remetem, para, em seguida, retornar a imagens, desta vez vistas aéreas de cidades, que the ocuparão as pranchas 106 a 123. A partir de 1972, o artista organizará exposições deste vasto acervo de imagens, trabalho paralelo ao de sua prática pictórica.

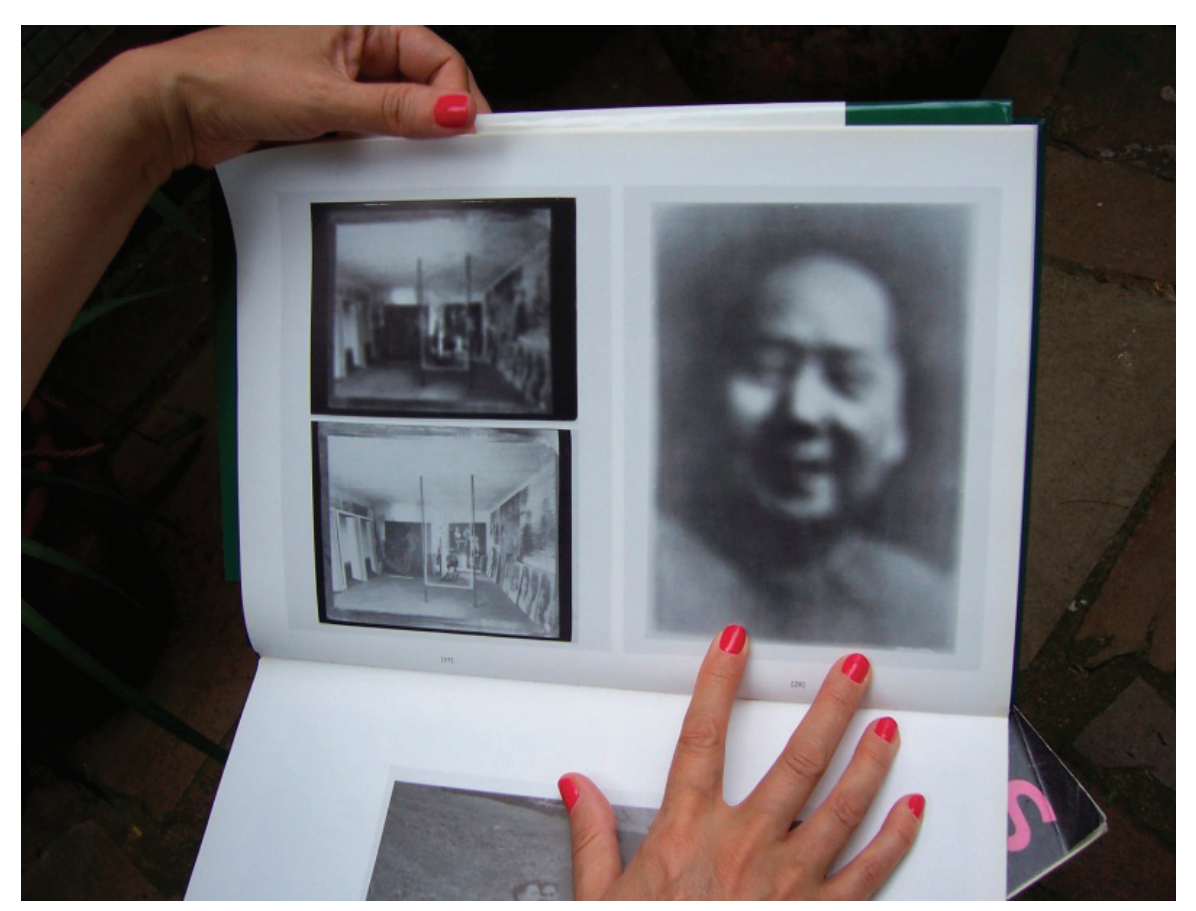

Figura 4: Gerhard Richter, Prancha número 28, fotografia desfocada, do líder comunista chinês Mao Tsé-Tung

Fonte: Atlas der Fotos, Collagen und Skizzen, 1998.

O que nos surpreende é que o artista não busca apenas constituir um catálogo enumerando fatos e imagens, mas busca elaborar, pela pintura, um equivalente para estas imagens todas. Reúne este grande acervo para retrabalhá-lo por meio de sua prática pictórica, elaborando manualmente, desta forma, imagens cotidianamente produzidas pela fotografia, fazendo a passagem do mecânico para o manual.

Uma série de pinturas deste artista, no meu entender muito densas, retoma o tema do terrorismo, partindo de imagens do grupo Baader-Meinhof veiculadas na imprensa (Richter, 1998, pranchas 472-478). O trágico destino dos integrantes deste grupo é transposto para fotografias e depois para telas pintadas a óleo, apenas em preto e branco, que mostram, em aspecto desfocado, cenas de prisão, confrontação, morte, bem como imagens de uma das terroristas quando jovem. 


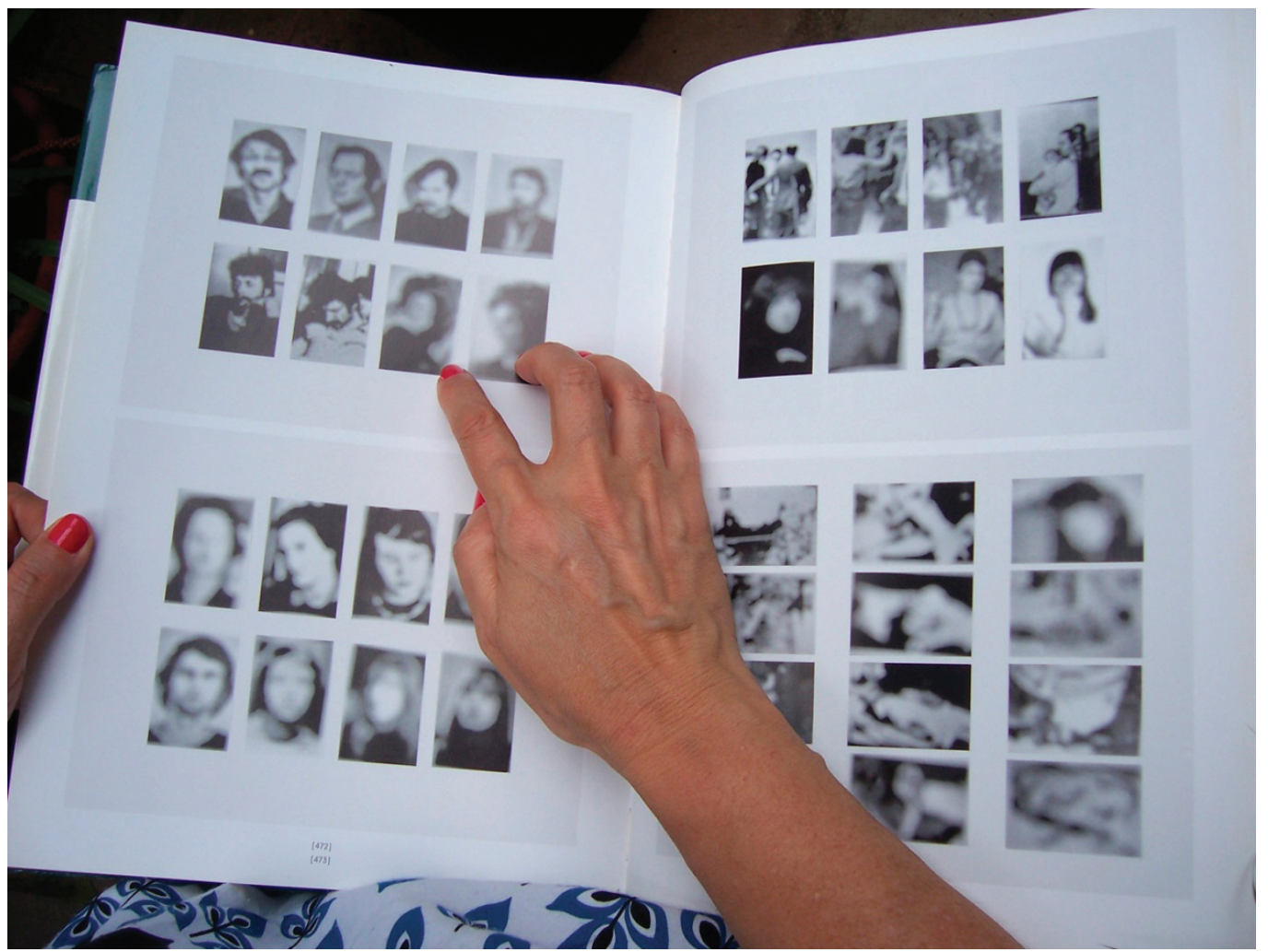

Figura 5: Gerhard Richter, Pranchas 472-478, fotografias desfocadas do grupo Baader-Meinhof Fonte: Livro Atlas der Fotos, Collagen und Skizzen, 1998.

Todas as imagens no catálogo, fotográficas e abstratas, se encontram reunidas para, de certa forma, atestar sua coesão com o gesto do artista que as reúne. Richter dirá, em um texto intitulado Notas:

Quando desenho - um homem ou um objeto - tenho que estar consciente da proporção, exatidão, abstração e distorção e assim por diante. Quando faço pintura a partir de uma foto, o pensamento consciente é interrompido. Não sei o que faço. Meu trabalho fica muito mais próximo do informal do que de qualquer tipo de "realismo". (...) Gostaria que tudo fosse muito evidente, simples e preciso e não gostaria de fazer nenhuma arte a não ser pintura qualquer, indeterminada. (...) gosto de tudo aquilo que não tem estilo: dicionários, fotos, natureza, eu e meus quadros. Pois o estilo é um ato de violência e não sou violento. (RICHTER apud FERREIRA, 2006, p. 116 -117)

Cabe salientar que para Richter, talvez pela coleção e classificação (assim como acreditava também Boltanski), seja possível que este grande acervo de fatos e gestos do mundo encontre seu espaço de memória no próprio museu.

Se observarmos atentamente o conjunto de trabalhos aqui analisados, veremos que cada um deles abre um leque distinto para a prática artística, testando os códigos de seu sistema ou aderindo a eles. Mesmo que profundamente diferentes em suas abordagens, o que reúne estes trabalhos é a capacidade de reapresentar a memória, de indagar sobre sua natureza e constituição, conferindo à arte uma 
função fundamental na cultura. ${ }^{8}$

A artista espanhola Lara Almarcegui mostraria na Bienal de São Paulo de 2007 um trabalho igualmente instigante para o assunto que tratamos neste texto. $\mathrm{Na}$ parede de uma das salas do pavilhão da bienal, ela afixaria com letras adesivadas o peso da cidade de São Paulo, obtido a partir de pesquisa realizada com o auxílio de uma equipe de engenheiros da prefeitura de São Paulo. Um intrincado cálculo foi possível com os recursos de uma planilha Excel, pela qual se obteve uma conta absurda, cuja soma era de 1.224.497.942 toneladas, que representaria o que havia na cidade de concreto, argamassa, tijolo, pedra, madeira, brita, aço, asfalto, telha, vidro, cobre, plástico, materiais que compõem as edificações da cidade. Paralelamente a isto, ela disponibilizava exemplares de um Guia de terrenos baldios na cidade de São Paulo. Com a publicação, Lara retomaria, dando um enfoque mais circunstancial aos espaços naturais, a operação de inventariar lugares, tal como apresentamos na obra de Ruscha e dos Becher. Guiados, de certa forma, pela publicação e pela informação descritiva de cada uma das locações propostas pela artista, caberia a um leitor interessado incursionar nestas áreas desocupadas de São Paulo para acompanhar o estado destes locais e sua transição.

Muitas questões surgem deste trabalho e propõem um modo crítico diferente das demais operações anteriormente mostradas. Estas remetem à posição crítica do artista, cuja ação tende a influir no presente: Como salvaguardar áreas livres da ocupação humana? Como influir na forma de nossas cidades? Como abrir clareiras no cotidiano e pensar a função dos espaços vagos numa cidade? Na seleção, há exemplos de todas as áreas da cidade. "A maioria deles, 15, no centro, como o polêmico terreno entre as ruas Jaceguay e Abolição, no Bexiga, contíguo ao Teatro Oficina, de Lina Bo Bardi (Itália, 1914/Brasil, 1992), e foco de uma polêmica sobre sua ocupação com um complexo cultural que poderá descaracterizar o conjunto arquitetônico da área". ${ }^{9}$

\footnotetext{
${ }^{8}$ Outra artista mostrada durante a palestra, Leila Danziguer, será observada na continuidade em outro texto em elaboração: "Leitura e reedição de imagens coletadas nas mídias: os artistas e o jornal". Deter-nos-emos mais especialmente na análise das operações de reedição realizadas por Leila, e por outros artistas, em trabalhos que se dão a partir da leitura de jornais cotidianos e das transformações deste suporte por eles operado.

${ }^{9}$ Encontramos uma menção ao Guia de Terrenos Baldios da cidade de São Paulo em um jornal eletrônico dedicado à construção, o que nos chamou muito a atenção. Neste caso, o trabalho parece ter suscitado comentários, a ponto de inserir-se em outros circuitos para além das revistas especializadas de arte. Disponível em: http://www.constructalia.com/br_BR/news/actualidad_detalle. jsp? idDoc $=1594074 \&$ idCat $=365923$. Acesso em: 15 maio 2009.
} 


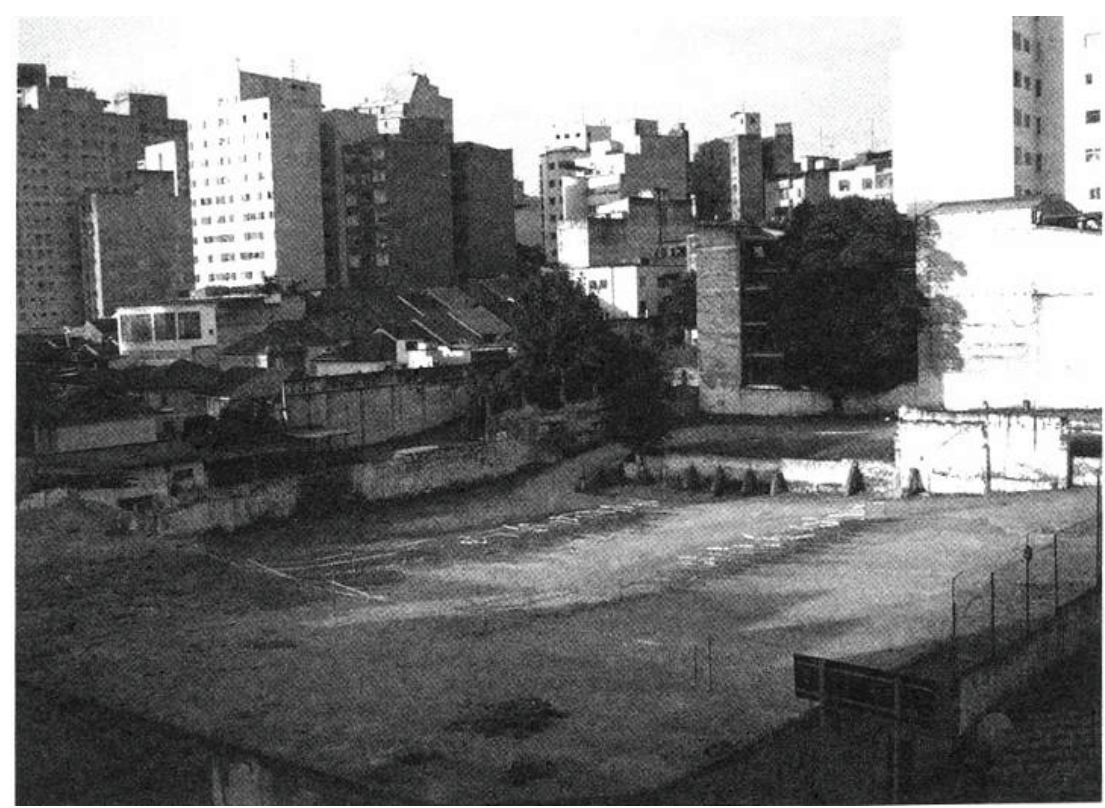

O terreno baldio corresponde a quase um quarteirão de casas demolidas recentemente, rodeadas de vários edifícios cujas paredes comuns dão para o terreno. Um deles é o Teatro Oficina, projetado por Lina Bo Bardi, que expõe sua parede comum diretamente para o terreno. $O$ córrego Japurá passa por baixo, correndo ao longo da Rua Japurá até o Vale do Anhangabaú.

Desde que se tenha um carro e se pague o estacionamento, pode-se entrar no terreno, ainda que esteja cercado. Também pode ser visto da via elevada Radial Leste. O Bairro do Bexiga, com uma origem de imigração italiana de artesãos e pequenos comerciantes, tinha uma forte tradição de mistura social graças aos teatros, cantinas e escolas de samba. A construção da via elevada quebrou o bairro, que dividido em dois começou a se deteriorar. Desde então, o grupo Silvio Santos foi adquirindo todos os terrenos e demolindo as edificações: $\mathrm{Na}$ Rua Abolição havia um grande edifício de uns 52 apartamentos ocupados por um cortiço até o final. Havia uma sinagoga que foi adquirida e demolida muito recentemente, em troca do compromisso de se construir uma nova. Junto ao Teatro Oficina, na Rua Jaceguay, havia casas e uma pensão muito antigas. O Grupo Sílvio Santos as comprou há mais de 10 anos e as demoliu depois de
This wasteland occupies a plot left empty by the recent demolition of houses and is enclosed by the walls of the surrounding buildings. One of them is Oficina Theatre, designed by Lina Bo Bardi, whose side wall gives directly onto the site. A small river, the Japurá, flows along the bottom edge alongside Japurá Street towards the Anhangabaú valley. Although the site is fenced off, it is used as a car park and so can be seen by anyone with a car willing to pay the parking fee. It can also be seen from Radial Leste viaduct which carries traffic over to the east of the city. The Bexiga District was originally a neighbourhood generated by Italian immigration with craftspeople and small businesses and had a tradition of social diversity due to the presence of theatres, bars and samba schools. When the flyover was built, the district was cut in two and began to deteriorate. Since then the Silvio Santos group have been buying up all the land and demolishing whatever stood there. In Abolição Street stood a big block of 52 apartments which had fallen into decline becoming an overcrowded slum. There was also a synagogue which was recently purchased and then pulled down on condition that a new one would be built elsewhere. Adjoining the Oficina Theatre, in Jaceguay Street, there were some very old houses and a boarding house. The Silvio Santos group bought them over ten

Figura 6: Lara Almarcegui, Guia de terrenos Baldios da Cidade de São Paulo (Zona Central).

Fonte: Catálogo da artista - Bienal de São Paulo, 2006.

A partir dos exemplos mostrados, foi-nos possível ver que a arte contemporânea tem uma vocação implicada a uma dimensão reflexiva. Há, em artistas que se dão à tarefa de reunir e constituir documentos e imagens para remontar o mundo, a vontade de trazer à tona os pontos de vista de suas diferentes experiências (Boltanski e Richter). Também encontramos outras ações artísticas de natureza mais ativa, no mundo real, que penetram em seu próprio interior para poder testemunhar e produzir um olhar singular a ser compartilhado (Ruscha e Becher). Ou ain- 
da, complementando as duas últimas práticas citadas, indicar ao público possibilidades de experimentar uma dimensão performativa e política (Almarcegui). ${ }^{10} \mathrm{Há}$, de fato, muitos movimentos que confluem num interesse comum: pensar a arte também como prática de salvaguarda de nossa memória, especialmente fecunda por se propor como instância de resistência crítica às sobreposições da Cultura.

\section{Bibliografia:}

Livros:

MOEGLIN-DELCROIX, Anne. Esthétique du livre d'artiste. Paris: Jean Michel Place/ Bibliothèque Nationale de France, 1997.

RICHTER, Gerhard. Notas, 1964-1965. In: FERREIRA, Glória; COTRIN, Cecília. Escritos de artista: anos 60-70. Rio de Janeiro: Jorge Zahar Editores, 2006.

SILVEIRA, Paulo. A Página Violada: da ternura à injúria na construção dos livros de artista. Porto Alegre: Editora da Universidade/UFRGS; Fumproarte/SMC, 2001.

STILES, Kristine; SELZ, Peter (Eds.). Theories and documents of contemporary art: a sourcebook of artist writings. Berkeley/Los Angeles: University of California Press, 1966.

Revistas:

BLISTÈNE, Bernard. Mécanique et Manuel dans I'Art de Gerhard Richter. In: Galeries Magazine, abril-maio, 1988.

SVESTKA, Jiri. Christian Boltanski. In: Galeries Magazine, abril-maio 1988.

\section{Catálogos:}

ALMARCEGUI, Lara. Guia de terrenos baldios de São Paulo: uma seleção dos lugares vazios mais interessantes da cidade. 27a Bienal Internacional de São Paulo, 2007.

BUSSMAN, Klaus. Bernd \& Hilla Becher - Typologies. Munich: Shirmer/Mosel, 1990.

RICHTER, Gerhard. Atlas der Fotos, Collagen und Skizzen. München: Galerie im Lenbachhaus, 1988.

Tese:

SILVEIRA, Paulo. As existências da narrativa no livro de artista. Tese. 2008. 321 p. (Doutorado em História, Teoria e Crítica) - Programa de Pós-Graduação em Artes Visuais, Universidade Federal do Rio Grande do Sul - Porto Alegre.

\footnotetext{
10 Um exemplo do que pode produzir a leitura de tal guia junto ao público mostra o quão fecunda é esta proposta artística cuja aparência é anódina, com 27.750 cópias impressas e distribuídas por ocasião da $27^{a}$ Bienal de São Paulo. Encontramos em um blog um interessante relato de um usuário do guia, que em 2008 o encontrou em um sebo em São Paulo, o que o levou a investigar mais sobre uma das áreas citadas, implicando-se no assunto proposto pela artista. Disponível em: http://www. carbonoquatorze.com.br/versaopaulo/2008/10/guia-dos-terrenos-baldios-de-so-paulo.html. Acesso em: $1^{\circ}$ dez. 2009.
} 


\section{Title:}

Facing the loss of archive

\section{Abstract:}

The recent report by the artist Sophie Hemon about the total loss of her archives of images sends one directly into the issue of memory and reconstruction. Starting from such a circumstantial introduction observations shall be made on the notion of editing, based on the analyses of contemporary artistic practices. Starting with Edward Ruscha, passing by Bernd and Hilla Becher, by Boltanski, Ritcher and Lara Amarcegui, a reflection will be carried out on the constitution of files in contemporary art, and about the potency of discursive articulation of certain images and their commercialization be it by means of an exposition, be it in a publication. How such practices of resingularization of the world are given back to the world as works, and what other issues do they bring to the field of art and culture?

\section{Keywords:}

Contemporary art; archive; memory; editing; publishing 